\title{
Improving Machining Accuracy for a Robotic Arm with Hybrid Kinematic Chains Based on Deformation Characteristics
}

Longfei Sun ( $\sim$ lfsun_neu@163.com )

Shenyang Ligong University https://orcid.org/0000-0002-4389-5364

Binghao Wang

Shenyang Ligong University

Shutao Huang

Shenyang Ligong University

Jinquan Li

Shenyang Ligong University

Lijin Fang

Northeastern University

\section{Research Article}

Keywords: Machining accuracy, Robotic arm, Hybrid kinematic chains, Deformation influence coefficient

Posted Date: December 15th, 2021

DOI: https://doi.org/10.21203/rs.3.rs-1157977/v1

License: (c) (i) This work is licensed under a Creative Commons Attribution 4.0 International License. Read Full License 


\title{
Improving Machining Accuracy for a Robotic Arm with Hybrid Kinematic Chains Based on Deformation Characteristics
}

\author{
Longfei Sun ${ }^{1,2}$, Binghao Wang', Shutao Huang ${ }^{1}$, Jinquan Lí ${ }^{1}$, Lijin Fang ${ }^{3}$ \\ 1. School of Mechanical Engineering, Shenyang Ligong University, Shenyang 110159, China \\ 2. Science and Technology Development Corporation, Shenyang Ligong University, Shenyang \\ 110003, China \\ 3. Faculty of Robot Science and Engineering, Northeastern University, Shenyang 110169, China \\ Corresponding author: Longfei Sun (lfsun_neu@163.com)
}

\begin{abstract}
The joint deformation has great influence on machining accuracy for a robotic arm. In this paper, the deformation characteristics of the robotic arm with hybrid kinematic chains is investigated in order to improve its machining accuracy. Firstly, the deformation model of the joints has been established based on the Strain energy method and Castigliano theorem according to the robot structure. Secondly, the deformation influence coefficient (DIC) is defined to investigate the deformation influence of main components on the end-effector, and the deformation characteristics are evaluated by the simulation. Finally, a small size robotic arm prototype is established and robotic drilling comparative experiments are conducted. The theoretical and experiment results show that the machining method can be selected according to the DIC, which the force can be applied to the components with better stiffness. On the other hand, the deformation of driving components can also be reduced when the DIC cannot be adjusted to meet the accuracy requirement.
\end{abstract}

Keywords: Machining accuracy, Robotic arm, Hybrid kinematic chains, Deformation influence coefficient

\section{Introduction}

As the development of robotic technology, the requirements of industrial robot for fine working and high precision machining are being proposed, such as milling and drilling. However, low stiffness characteristics limit the application of industrial robots in the field of precision manufacturing [1]. Theoretical and experimental results show that the stiffness of a serial industrial robot is usually lower than $1 \mathrm{~N} / \mu \mathrm{m}$, while the stiffness of a CNC machine is usually greater than $50 \mathrm{~N} / \mu \mathrm{m}[2]$. In addition, the limitation of parallel-structured robots (such as Exechon and Tricept) is 
their restricted workspace, although they have better stiffness. Luo et al. [3] proposes a heavy-load and high-precision friction stir welding robot for welding large and complex thin-walled aluminum alloy 7075 surfaces. Xu et al. [4] designed a novel six degrees-of-freedom (DOF) hybrid kinematic machine for polishing. Janez et al. [5] described an approach to improve the robot's accuracy based on its structural properties which considering manipulability, structural stiffness, structure inertial, damping ratios, and natural frequencies.

Stiffness analysis and optimization is an effective method for industrial robots to improve the machining accuracy. $\mathrm{Bu}$ et al. [1] proposed a Cartesian compliance model to describe the robot stiffness in Cartesian space, and a quantitative index of the robotic processing performance is defined based on the compliance model. Xie et al. [6] built the mathematical models of machining error considering both kinematic errors and joint stiffness using speed and force adjoint transformation. Wei et al. [7] presents a finite element fitting method to analysis the stiffness distribution of the robot, and the low-, medium-and high-stiffness regions of the mechanism are shown through the stiffness distribution diagram. Zhao et al. [8] proposes a method of constructing the hybrid stiffness index to enhance the stiffness of the serial robot in completing friction stir welding tasks. The sigmoid function is used to process the dexterity or joint limit index and applies it to the stiffness index as a weight coefficient. The dimension synthesis of the serial robot is completed by maximizing the global soft stiffness index. Li et al. [9] divide the positioning errors into the axial deformation error and the radial deformation error, and the positioning errors compensation method considering the end load and gravity based on the stiffness modelling is proposed. Zhang et al. [10] investigate the influence of robot stiffness properties on machining quality in drilling application, and the matching criterion of robotic drilling posture and thrust force is proposed, so as the optimized value of the pressing force can be predicted for stable machining. Bu et al. [11] presents a modeling method of the Cartesian compliance for a drilling robot, the stiffness characterization in the axial direction and the diversity of the axial stiffness for different posture are investigated. Lin et al. [12] presents an optimization method of the robot by taking the contour errors as the optimization index, and the optimal poses are obtained by minimizing contour error through a discrete searching algorithm.

Error compensation is another way to decrease the positioning error for robotic machining. Zhu et al. [13] proposes a method which contains the two-dimensional manifold that reduces the dimensionality of the workspace, in order to improve the efficiency of error compensation. Yin et al. [14] proposes multi-iteration error compensation technology considering the coupling relationship 
between deformation and compensation, and a discrete control system for error compensation is constructed based on the milling force and errors predicted model. Ye et al. [15] focus on the contour errors of robotic machining, and a machining performance index is proposed to optimize the task-dependent workpiece placement. Li et al. [16] proposed a joint stiffness identification algorithm for serial robot, and a deformation compensation algorithm for the accuracy improvement. A drilling operation experiment is performed to identify the joint stiffness identification algorithm and the deformation compensation algorithm. Although the robot pose with respect to the workpiece can be measured and modified through a multi-sensor measurement system, the inaccuracies of the test scenario and slippage on the workpiece impact the machining accuracy [17]. However, it is difficult to obtain satisfactory machining accuracy for robotic drilling even if the errors are compensated after the deformation generated.

Precision design is also an important approach to guarantee the accuracy of industrial robots. Luo et al. [18] propose a structural optimization method based on sensitivity analysis of the variable section of a slender robotic arm. The sensitivity analysis method and the sequential linear programming strategy are developed. The local sensitivity index is defined based on the projection theory of spatial vector to evaluate the contribution of an error component in a definite pose, and the results show that the pose accuracy can be increased greatly by improving very few error components [19]. Wang et al. [20] pay attention to the force transmission process of the robot, three indices are proposed which are forward force sensitivity, reverse force sensitivity, and overall force sensitivity. Also, the structural optimization design schemes are presented based on the above indices. The ways of end-effector configuration affect the deformation of the robotic joint, the passive torque can be reduced to improve positioning accuracy due to selecting the proper configuration [21]. Luo et al. [22] uses finite element analysis for designing the ram structure of friction stir welding robots, the lightweight design of the ram structure can be achieved through the optimization, and the welding precision can be effectively improved.

In this paper, a robotic arm with hybrid open- and closed-loop chains is introduced. In order to evaluate the machining accuracy of the hybrid robotic arm, the deformation characteristics of the robotic arm are investigated by proposing the deformation influence coefficient (DIC). Based on the deformation characteristics analysis, the machining accuracy improvement method is proposed. Then, a small size robotic arm prototype is established, and the comparative drilling experiments are conducted with different poses and components. The results indicate that the proposed deformation 
analysis method is simple, easy to use and effective.

The paper is structured as follows. In section 2, the structure of the robotic arm with hybrid chains is described. In section 3, the robotic joint deformation model is studied, and the effect of is analyzed. In section 4, the robotic drilling experiments are conducted. Finally, the paper is concluded in section 5 .

\section{Robotic Arm Description}

In order to improve machining accuracy and maintain large workspace at the same time, a robotic arm with hybrid open- and closed-loop kinematic chains is proposed. The robotic arm has 5 DOF which composes of the waist, the big arm, the small arm and the wrist joint, as shown in Figure 1. The big arm and small arm are connected in series to form an open loop chain, while the frame of robotic arm itself forms a closed loop chain. The big arm and small arm are composed of a multi-link parallelogram frame, and the electric cylinder is installed on the diagonal of the parallelogram which forms a truss structure. The pitching action of the robotic arm is realized by controlling the telescopic motion of the electric cylinders.

The long link of the parallelogram in the robotic arm is $1000 \mathrm{~mm}$ and the short link is $460 \mathrm{~mm}$; the width of the long link is $220 \mathrm{~mm}$ and thickness is $60 \mathrm{~mm}$ in the small arm; the width of the long link is $300 \mathrm{~mm}$ and the thickness is $70 \mathrm{~mm}$ in the big arm. The structure of the robotic arm and its workspace in $x-o-z$ plane are shown in Figure 1.

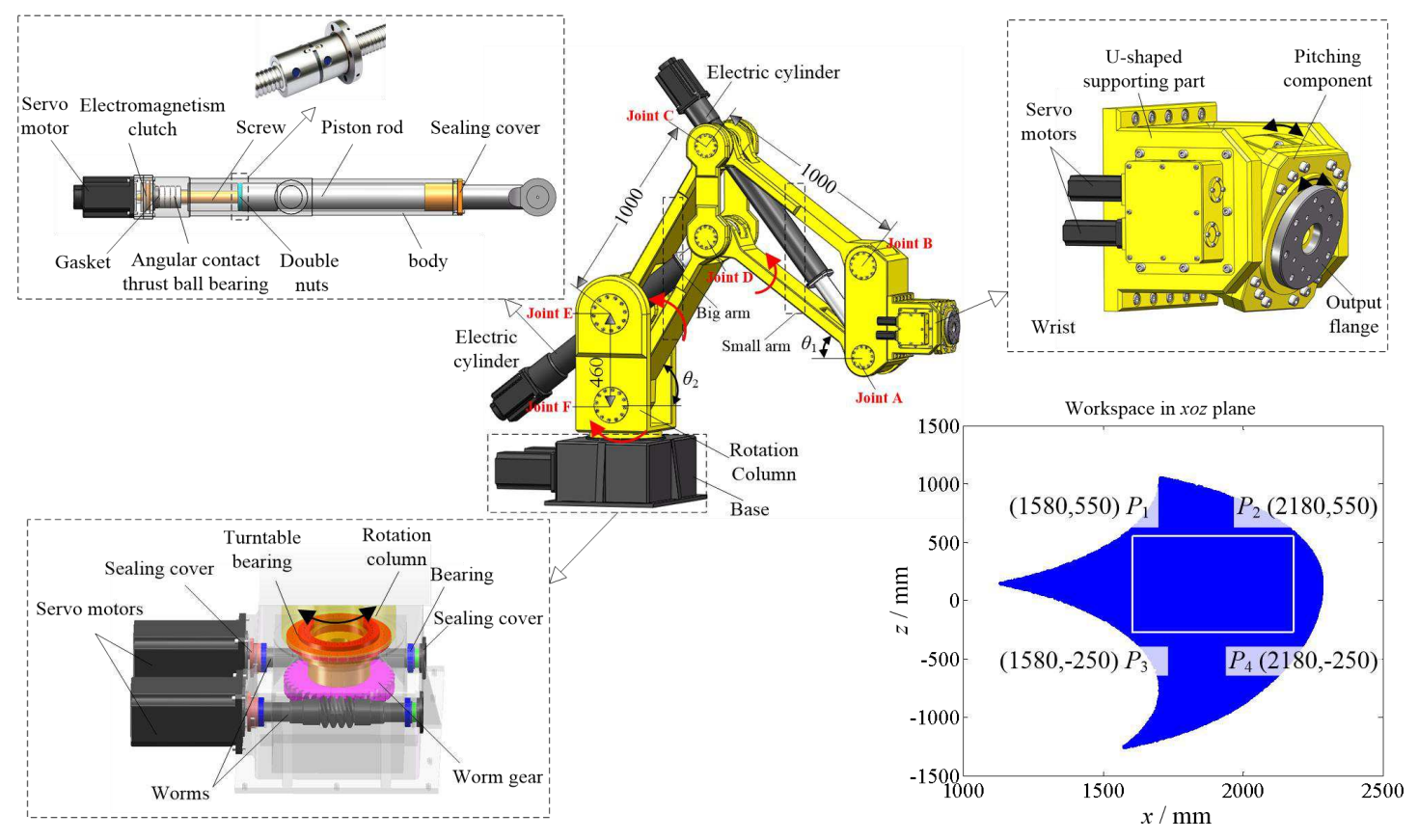

Fig. 1 The structure of the robotic arm with hybrid kinematic chains 


\section{Joint Deformation Modeling and Analysis}

\subsection{Deformation Modeling of Robotic Joint}

Under the action of external load, the deformation of robotic components will eventually be reflected to the end of the robot, which will affect the machining accuracy of the robot. The relationship between the deformation and the external force can be expressed as

$$
\delta \mathbf{S}_{p}=\left[\begin{array}{lll}
\delta \mathrm{S}_{x} & \delta \mathrm{S}_{y} & \delta \mathrm{S}_{z}
\end{array}\right]^{T}=\mathbf{C F}_{e}
$$

where, $\boldsymbol{C}$ represents the compliance matrix; $F_{\mathrm{e}}$ represents the external force, which can be expressed as

$$
\mathbf{F}_{e}=\left[\begin{array}{lll}
F_{e x} & F_{e y} & F_{e z}
\end{array}\right]^{T}
$$

The comprehensive deformation of the robotic arm is superposed by the deformation of each joint, and the joint deformation is composed of the driving components' deformation and the links' deformation. In order to investigate the influence of each component deformation on the comprehensive deformation, the joint deformation model is established as follows. The robotic arm is established with hybrid kinematic chains, which the links are connected with joints. Therefore, the robotic joint deformation model can be established based on Strain energy method and Castigliano theorem. The load on link AD and electric cylinder AC causes the deformation of joint A along $x$ direction and $z$ direction, respectively. Similarly, the load on link FD and electric cylinder ED causes the deformation of joint $\mathrm{D}$ along $x$ direction and $z$ direction, respectively. The deformation of short and thick links $\mathrm{AB}, \mathrm{CD}$ and $\mathrm{EF}$ is ignored So, the deformation of joint $\mathrm{A}$ along $x$ direction can be expressed as:

$$
\delta \mathrm{A}_{x}=\frac{\partial U_{\mathrm{A}}}{\partial F_{\mathrm{A} x}}=\frac{F_{\mathrm{AC}}}{K_{\mathrm{AC}}} \frac{\partial F_{\mathrm{AC}}}{\partial F_{\mathrm{A} x}}+\frac{F_{\mathrm{AD}}}{K_{\mathrm{AD}}} \frac{\partial F_{\mathrm{AD}}}{\partial F_{\mathrm{A} x}}
$$

where, $U_{\mathrm{A}}$ represents the strain energy of joint $\mathrm{A}, F_{\mathrm{Ax}}$ represents the force in $x$ direction of joint A, $K_{\mathrm{AC}}$ represents the equivalent stiffness of electric cylinder $\mathrm{AC}, F_{\mathrm{AC}}$ represents the force of electric cylinder $\mathrm{AC}, K_{\mathrm{AD}}$ represents the equivalent stiffness of link $\mathrm{AD}, F_{\mathrm{AD}}$ represents the force of link $\mathrm{AD}$.

The deformation of joint $\mathrm{A}$ along $z$ direction can be expressed as:

$$
\delta \mathrm{A}_{z}=\frac{\partial U_{\mathrm{A}}}{\partial F_{\mathrm{A} z}}=\frac{F_{\mathrm{AC}}}{K_{\mathrm{AC}}} \frac{\partial F_{\mathrm{AC}}}{\partial F_{\mathrm{A} z}}+\frac{F_{\mathrm{AD}}}{K_{\mathrm{AD}}} \frac{\partial F_{\mathrm{AD}}}{\partial F_{\mathrm{A} z}}
$$


where, $F_{\mathrm{Az}}$ represents the force in $z$ direction of joint $\mathrm{A}$.

The deformation of joint $\mathrm{D}$ along $x$ direction can be expressed as:

$$
\delta \mathrm{D}_{x}=\frac{\partial U_{\mathrm{D}}}{\partial F_{\mathrm{D} x}}=\frac{F_{\mathrm{DE}}}{K_{\mathrm{DE}}} \frac{\partial F_{\mathrm{DE}}}{\partial F_{\mathrm{D} x}}+\frac{F_{\mathrm{DF}}}{K_{\mathrm{DF}}} \frac{\partial F_{\mathrm{DF}}}{\partial F_{\mathrm{D} x}}
$$

where, $U_{\mathrm{D}}$ represents the strain energy of joint $\mathrm{D}, F_{\mathrm{Dx}}$ represents the force in $x$ direction of joint $\mathrm{D}$, $K_{\mathrm{DE}}$ represents the equivalent stiffness of electric cylinder DE, $F_{\mathrm{DE}}$ represents the force of electric cylinder DE, $K_{\mathrm{DF}}$ represents the equivalent stiffness of link DF, $F_{\mathrm{DF}}$ represents the force of link DF.

The deformation of joint $\mathrm{D}$ along $z$ direction can be expressed as:

$$
\delta \mathrm{D}_{\mathrm{z}}=\frac{\partial U_{\mathrm{D}}}{\partial F_{\mathrm{D} z}}=\frac{F_{\mathrm{DE}}}{K_{\mathrm{DE}}} \frac{\partial F_{\mathrm{DE}}}{\partial F_{\mathrm{D} z}}+\frac{F_{\mathrm{DF}}}{K_{\mathrm{DF}}} \frac{\partial F_{\mathrm{DF}}}{\partial F_{\mathrm{D} z}}
$$

where, $F_{\mathrm{Dz}}$ represents the force in $z$ direction of joint $\mathrm{D}$.

In order to evaluate the deformation of each component separately and clearly, we define the deformation influence coefficient (DIC) $\sigma$, which can be expressed as:

$$
\begin{aligned}
& \left\{\begin{array}{l}
\sigma \mathrm{AC}_{\mathrm{A} x}=F_{\mathrm{AC}} \frac{\partial F_{\mathrm{AC}}}{\partial F_{\mathrm{A} x}} \\
\sigma \mathrm{AC}_{\mathrm{A} z}=F_{\mathrm{AC}} \frac{\partial F_{\mathrm{AC}}}{\partial F_{\mathrm{A} z}}
\end{array}\right. \\
& \left\{\begin{array}{l}
\sigma \mathrm{AD}_{\mathrm{A} x}=F_{\mathrm{AD}} \frac{\partial F_{\mathrm{AD}}}{\partial F_{\mathrm{A} x}} \\
\sigma \mathrm{AD}_{\mathrm{A} z}=F_{\mathrm{AD}} \frac{\partial F_{\mathrm{AD}}}{\partial F_{\mathrm{A} z}}
\end{array}\right. \\
& \left\{\begin{array}{l}
\sigma \mathrm{DE}_{\mathrm{D} x}=F_{\mathrm{DE}} \frac{\partial F_{\mathrm{DE}}}{\partial F_{\mathrm{D} x}} \\
\sigma \mathrm{DE}_{\mathrm{D} z}=F_{\mathrm{DE}} \frac{\partial F_{\mathrm{DE}}}{\partial F_{\mathrm{D} z}}
\end{array}\right. \\
& \left\{\begin{array}{l}
\sigma \mathrm{DF}_{\mathrm{D} x}=F_{\mathrm{DF}} \frac{\partial F_{\mathrm{DF}}}{\partial F_{\mathrm{D} x}} \\
\sigma \mathrm{DF}_{\mathrm{D} z}=F_{\mathrm{DF}} \frac{\partial F_{\mathrm{DF}}}{\partial F_{\mathrm{D} z}}
\end{array}\right.
\end{aligned}
$$

According to the deformation model of the robotic arm, the deformation of the robot largely depends on the DIC, in addition, the component stiffness is also the main factor affecting the deformation. 


\subsection{Simulation Results and Analysis}

According to the structural parameters of the proposed hybrid robotic arm, the deformation model is established and the deformation characteristics are simulated by the MATLAB software. First, the effects of the link $\mathrm{AD}$ and the electric cylinder $\mathrm{AC}$ on the deformation of joint $\mathrm{A}$ along $x$ and $z$ directions are investigated.

Figure 2(a) shows the ratio of DIC $\sigma \mathrm{AC}_{\mathrm{Ax}}$ to $\sigma \mathrm{AD}_{\mathrm{A} x}$, and Figure 2(b) shows the DIC ratio of $\sigma \mathrm{AC}_{\mathrm{A} z}$ to $\sigma \mathrm{AD}_{\mathrm{Az}}$. The simulation results show that the link $\mathrm{AD}$ and the electric cylinder $\mathrm{AC}$ bear axial tension force or compression force at the same time in the workspace. In Figure 2(a), the ratio of $\sigma \mathrm{AC}_{\mathrm{A} x} / \sigma \mathrm{AD}_{\mathrm{A} x}$ shows the relative influence of electric cylinder $\mathrm{AC}$ and link $\mathrm{AD}$ on the joint $\mathrm{A}$ in $x$ direction. The variation range of $\sigma \mathrm{AC}_{\mathrm{A} x} / \sigma \mathrm{AD}_{\mathrm{A} x}$ is $0.10 \sim 0.85$. When the small arm is retracted, the $\mathrm{DIC}$ ratio of the electric cylinder $\mathrm{AC}$ relative to connecting link $\mathrm{AD}$ on the joint $\mathrm{A}$ along $x$ direction reaches to the maximum value 0.85 , while, when the small arm is unfolded, the ratio of force influence coefficient reaches to the minimum value 0.10 . Therefore, making the small arm work in a relatively unfolded state can make the force act on link $\mathrm{AD}$ that has better rigidity, which is conducive to reducing the deformation in $x$ direction.

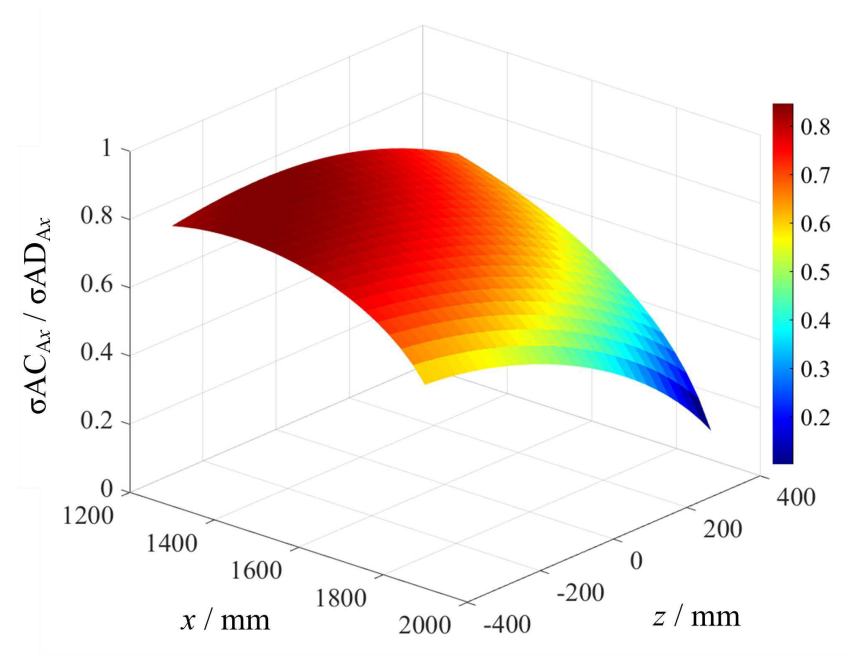

(a)

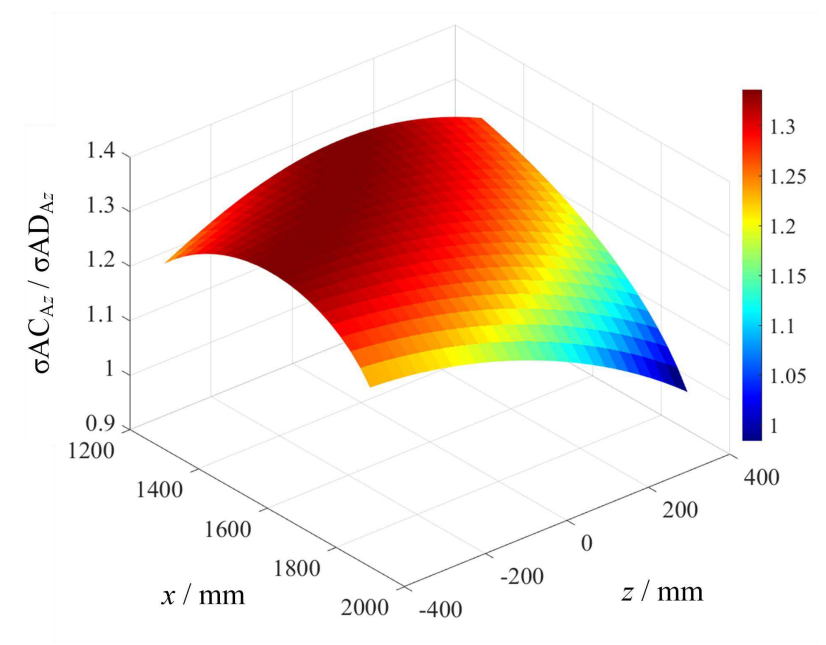

(b)

Fig. 2 The ratio of deformation influence coefficient (DIC) for joint A

Similarly, the value of $\sigma \mathrm{AC}_{\mathrm{A} z} / \sigma \mathrm{AD}_{\mathrm{A} z}$ shows the relative influence of electric cylinder $\mathrm{AC}$ and link $\mathrm{AD}$ on the joint $\mathrm{A}$ along $z$ direction. The variation range of $\sigma \mathrm{AC}_{\mathrm{Az} z} / \sigma \mathrm{AD}_{\mathrm{A} z}$ is $0.98 \sim 1.34$, as shown in Figure 2(b). The simulation results show that when the small arm is unfolded, the ratio of $\mathrm{DIC} \sigma \mathrm{AC} \mathrm{A} z$ 
is equivalent to $\sigma \mathrm{AD}_{\mathrm{Az}}$. In other states, the $\mathrm{DIC}$ of electric cylinder $\mathrm{AC}$ on the deformation of joint $\mathrm{A}$ along $\mathrm{z}$ direction is a little greater than that of the link AD.

Figure 3(a) shows the DIC of joint D along $x$ direction. In some area of the workspace, such as partially unfolded area, the sign of DIC $\sigma \mathrm{DF}_{\mathrm{D} x}$ changes while the sign of DIC $\sigma \mathrm{DE} \mathrm{D} x$ remains unchanged. Therefore, selecting the area with different DIC sign is benefit to reduce the deformation of joint $\mathrm{D}$ along $x$ direction.

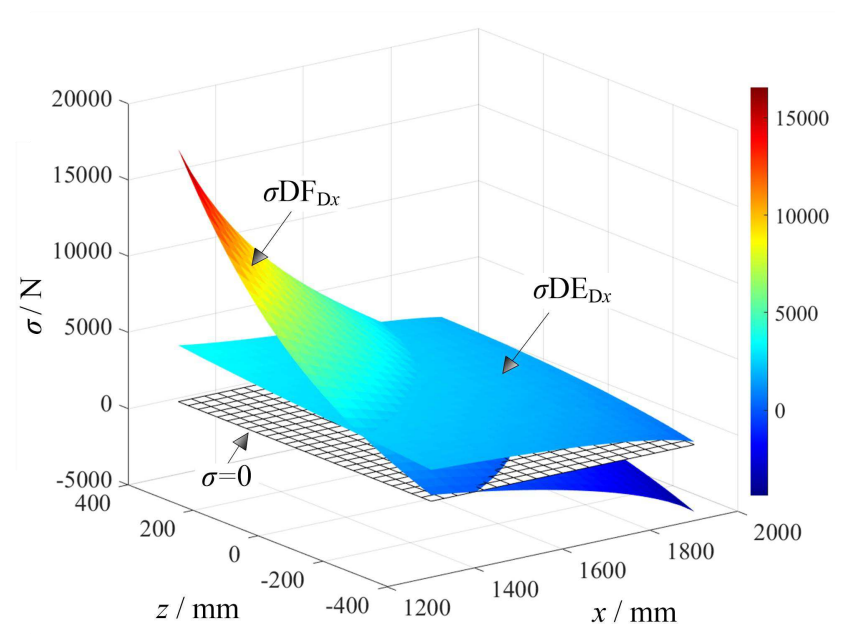

(a)

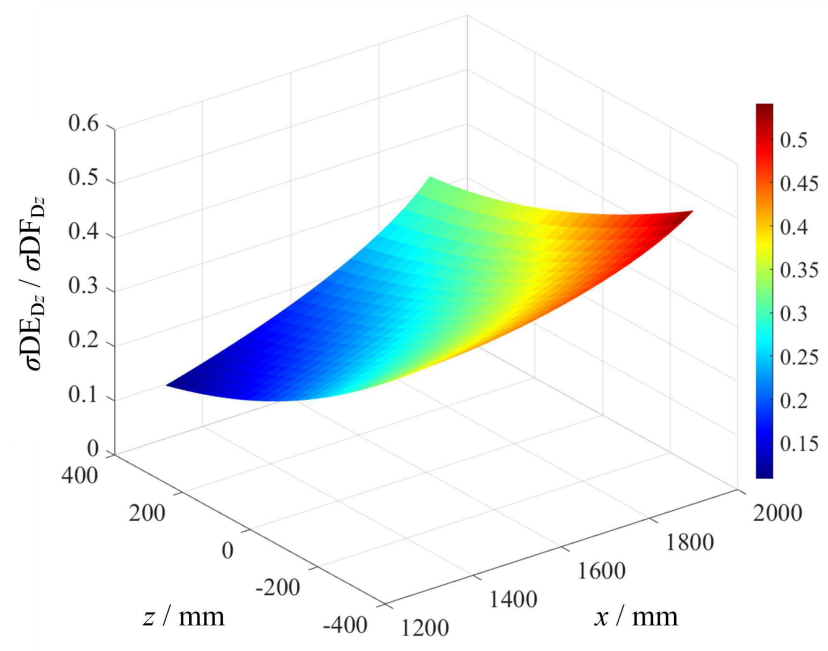

(b)

Fig. 3 The value and the ratio of DIC for joint D

The value of $\sigma \mathrm{DE}_{\mathrm{D} z} / \sigma \mathrm{DF}_{\mathrm{D} z}$ shows the relative influence of electric cylinder $\mathrm{DE}$ and link $\mathrm{DF}$ on the joint $\mathrm{D}$ along $z$ direction, as shown in Figure 3(b), and the variation range of $\sigma \mathrm{DE}_{\mathrm{D} z} / \sigma \mathrm{DF} \mathrm{D}_{\mathrm{D} z}$ is $0.11 \sim 0.54$. According to the simulation results, when the big arm is unfolded, the DIC $\sigma \mathrm{DE} \mathrm{D}_{\mathrm{D} z}$ is increased relative to the $\mathrm{DIC} \sigma \mathrm{DF}_{\mathrm{D} z}$. Making the big arm working in the retracted state will reduce the deformation of the joint $\mathrm{D}$ along $z$ direction.

The equivalent stiffness of electric cylinders is usually lower than that of the links, therefore, making the DIC of the links larger than that of the electric cylinders as much as possible is conductive to reducing the deformation of robotic joints. Besides, the DIC of different areas in the workspace are different, and the directions of machining force need to be considered according to the accuracy requirement. In addition, reducing the deformation of flexible parts which have relative weak stiffness, that is, improving the equivalent stiffness $K$ in Equations (3-6) is a direct way to deduce the deformation of the robotic arm. 


\section{Robotic Drilling Experiment}

In order to verify the deformation characteristics of the proposed robotic arm, a small size prototype is established that the length of the long link and short link in parallelogram frame are 360mm and $240 \mathrm{~mm}$, respectively, and the width of the links is $66 \mathrm{~mm}$. The frame structure of the robot prototype is made of 6061 aluminum alloy. The robotic drilling experimental system is established which includes robotic arm, spindle feed mechanism, motorized spindle, drilling bit, workpiece and fixture, as shown in Figure 4. In order to ensure that the axes of the spindle and the drill bit are perpendicular to the plane of the worktable, the probe of the dial indicator is in contact with the moving end face of the spindle feeding mechanism along the $\mathrm{X}$ direction and $\mathrm{Y}$ direction respectively, and the normal angle between the spindle axis and the worktable is obtained by observing the reading change of the dial indicator during the spindle feeding process. After repeated adjustment, the included angle between the spindle axis and the normal of the horizontal plane of the worktable is less than $0.01^{\circ}$.

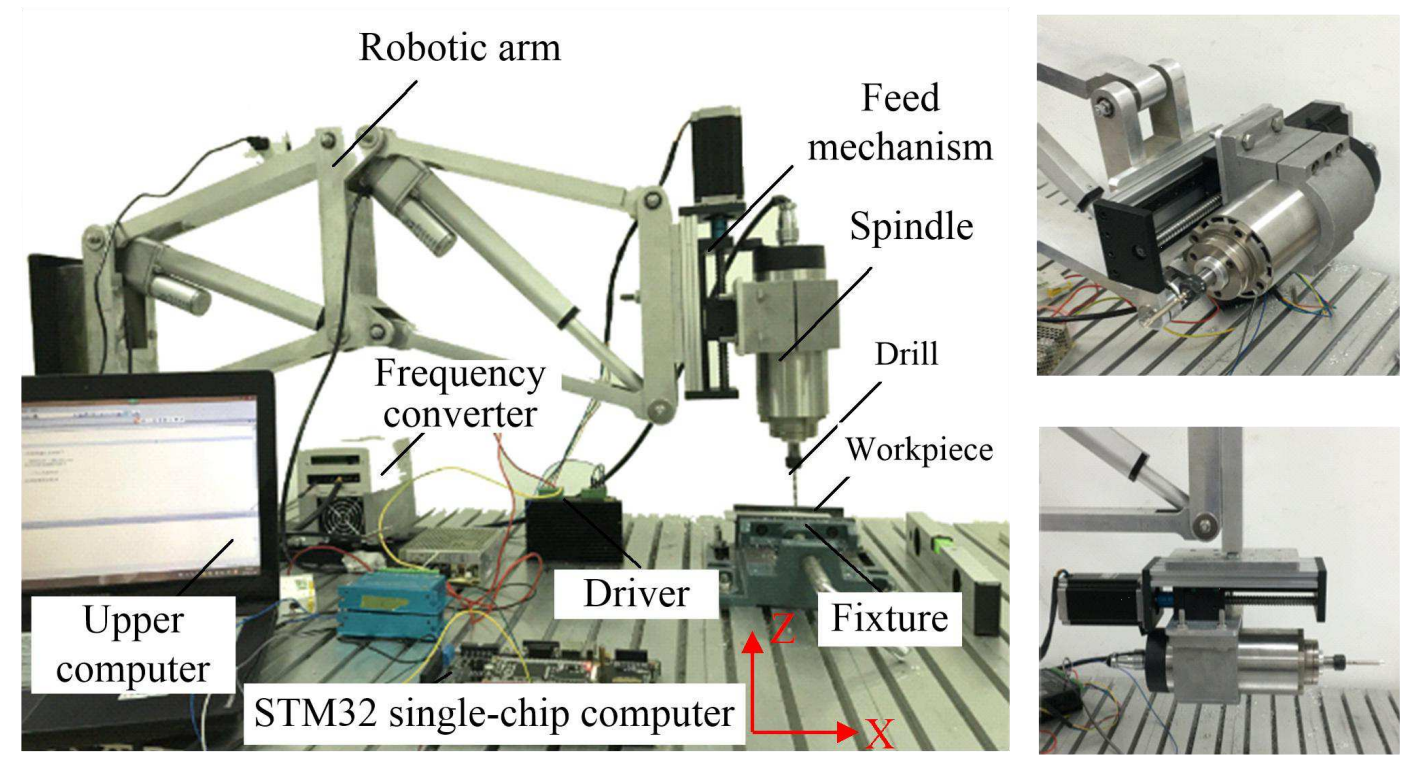

Fig. 4 Robotic drilling experimental system

The parameters of the drilling experiment are shown in Table 1. An air-cooled spindle motor is selected as the motorized spindle for the machining. The power of the spindle motor is $1.5 \mathrm{KW}$, and the maximum speed is $24000 \mathrm{rpm}$, the radial runout error is only $2 \mu \mathrm{m}$. The high-speed steel twist bit is selected in the experiment. BXTL150 series electric cylinders are selected for driving the robotic arm. The workpiece to be processed is made of 6061 aluminum alloy, with a length of $120 \mathrm{~mm}$, a width of $60 \mathrm{~mm}$ and a thickness of $5 \mathrm{~mm}$. The maximum axial drilling force is about $49.2 \mathrm{~N}$ for 
drilling a $5 \mathrm{~mm}$ diameter hole. Fourteen holes to be drilled on the workpiece which marked as $\mathrm{H} 1 \sim \mathrm{H} 14$, respectively.

Table 1 Robotic drilling parameters in experiments

\begin{tabular}{cc}
\hline Drilling parameter & Value \\
\hline Bit angle $\left(^{\circ}\right)$ & 120 \\
Bit diameter $(\mathrm{mm})$ & 5 \\
Bit length $(\mathrm{mm})$ & 80 \\
Feed speed $(\mathrm{mm} / \mathrm{min})$ & 120 \\
Spindle speed $(\mathrm{r} / \mathrm{min})$ & 3200 \\
Cooling mode & None \\
\hline
\end{tabular}

Firstly, two groups of comparative drilling experiments are conducted with two different poses. Pose I has the angle $\theta_{1} 25^{\circ}$ and angle $\theta_{2} 35^{\circ}$, which the ratio of DIC $\sigma \mathrm{AC}_{\mathrm{A} x} / \sigma \mathrm{AD}_{\mathrm{A} x}$ is 0.4 . Pose II has the angle $\theta_{1} 45^{\circ}$ and angle $\theta_{2} 35^{\circ}$, which the ratio of $\mathrm{DIC} \sigma \mathrm{AC}_{\mathrm{A} x} / \sigma \mathrm{AD}_{\mathrm{Ax}}$ is 0.6 . The holes from $\mathrm{H} 1$ to H14 will be drilled in turn. The experiment results of drilling $5 \mathrm{~mm}$ holes by the robotic arm are shown in Figure 5. From the overall experimental results, it can be seen that the consistency is good for robotic drilling.
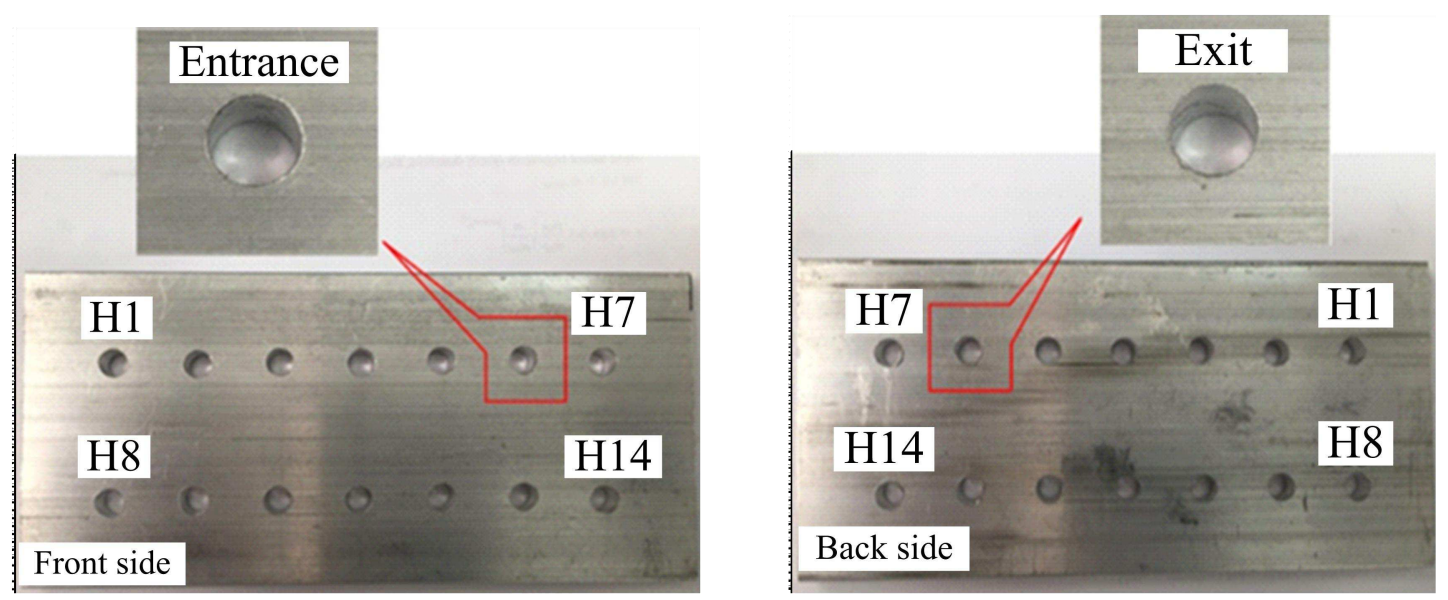

Fig. 5 Drilling experiment effect for drilling 6061 aluminum alloy

The results of the axial angle error of the holes obtained from the experimental measurement are shown in Table 2. In the experiment, the maximum angle error of the drilled holes along $z$ direction at pose $\mathrm{I}$ is $0.93^{\circ}$, and the average angle error is $0.75^{\circ}$. Besides, the maximum angle error at pose II is $0.98^{\circ}$, and the average angle error is $0.92^{\circ}$. 
Table 2 Angular errors drilled along z direction (6061 aluminum alloy)

\begin{tabular}{ccc}
\hline No. & Pose I & Pose II \\
\cline { 2 - 3 } H1 & Angle error $\Delta\left(^{\circ}\right)$ & Angle error $\Delta\left(^{\circ}\right)$ \\
\hline H2 & 0.81 & 0.90 \\
H3 & 0.75 & 0.87 \\
H4 & 0.87 & 0.90 \\
H5 & 0.93 & 0.89 \\
H6 & 0.56 & 0.93 \\
H7 & 0.65 & 0.96 \\
H8 & 0.78 & 0.94 \\
H9 & 0.74 & 0.90 \\
H10 & 0.69 & 0.89 \\
H11 & 0.90 & 0.98 \\
H12 & 0.82 & 0.95 \\
H13 & 0.56 & 0.93 \\
H14 & 0.73 & 0.91 \\
\hline
\end{tabular}

The bending deformation of the bit causes the axial angle error for the drilled holes under the external force, and causes the roundness error of the theoretical circular hole to be drilled at the same time. The diameter of the $5 \mathrm{~mm}$ hole drilled by the robotic arm at the above two pose is measured at different circumference angles, as shown in Figure 6. In addition, the actual diameters of the drilled holes $(\mathrm{H} 1 \sim \mathrm{H} 14)$ at pose I are shown in Table 3.

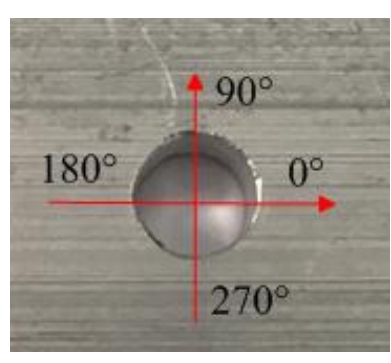

(a) Drilled hole

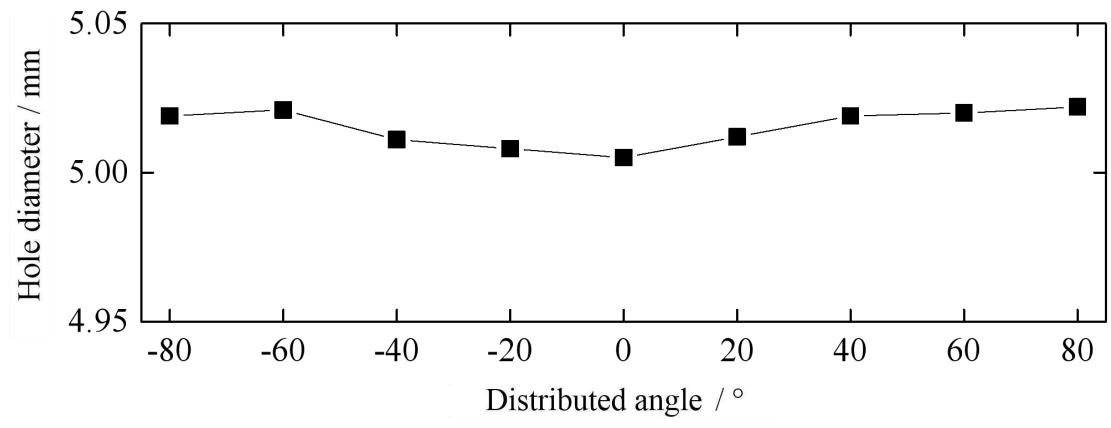

(b) Diameter distribution of $\mathrm{H} 1$ hole at pose I

Fig.6 Diameter distribution of robotic drilling holes 
Table 3 Actual diameters of the drilled holes at pose I (6061 aluminum alloy)

\begin{tabular}{cccccccccc}
\hline & $-80^{\circ}$ & $-60^{\circ}$ & $-40^{\circ}$ & $-20^{\circ}$ & $0^{\circ}$ & $20^{\circ}$ & $40^{\circ}$ & $60^{\circ}$ & $80^{\circ}$ \\
\hline H1 & 5.019 & 5.021 & 5.011 & 5.008 & 5.005 & 5.012 & 5.019 & 5.020 & 5.022 \\
H2 & 5.020 & 5.019 & 5.026 & 5.013 & 5.009 & 5.015 & 5.012 & 5.010 & 5.029 \\
H3 & 5.018 & 5.009 & 5.012 & 5.016 & 5.026 & 5.015 & 5.024 & 5.012 & 5.011 \\
H4 & 5.007 & 5.018 & 5.031 & 5.025 & 5.021 & 5.019 & 5.021 & 5.013 & 5.007 \\
H5 & 5.001 & 5.002 & 5.008 & 5.009 & 5.001 & 5.013 & 5.010 & 5.009 & 5.009 \\
H6 & 5.029 & 5.027 & 5.038 & 5.029 & 5.011 & 5.015 & 5.012 & 5.041 & 5.020 \\
H7 & 5.020 & 5.030 & 5.048 & 5.049 & 5.041 & 5.020 & 5.021 & 5.029 & 5.021 \\
H8 & 5.028 & 5.029 & 5.022 & 5.026 & 5.015 & 5.031 & 5.040 & 5.029 & 5.026 \\
H9 & 5.029 & 5.018 & 5.019 & 5.023 & 5.032 & 5.029 & 5.015 & 5.006 & 5.005 \\
H10 & 5.029 & 5.040 & 5.030 & 5.021 & 5.038 & 5.025 & 5.046 & 5.040 & 5.045 \\
H11 & 5.041 & 5.048 & 5.048 & 5.048 & 5.046 & 5.029 & 5.018 & 5.012 & 5.021 \\
H12 & 5.009 & 5.012 & 5.013 & 5.030 & 5.042 & 5.039 & 5.015 & 5.021 & 5.042 \\
H13 & 5.025 & 5.020 & 5.021 & 5.035 & 5.038 & 5.012 & 5.020 & 5.029 & 5.028 \\
H14 & 5.034 & 5.039 & 5.015 & 5.022 & 5.020 & 5.032 & 5.026 & 5.021 & 5.020 \\
\hline
\end{tabular}

As shown in Table 3, the maximum tolerance of all the holes drilled on the 6061-aluminum alloy workpiece is $0.036 \mathrm{~mm}$, and the tolerance level of all holes can reach to IT10, in which the most holes can reach to IT9 at pose I. The same drilling process is conducted at pose II, and the actual diameters of the drilled holes are also measured using the same method, which are not list in detail in the paper. Correspondingly, the tolerance level of the holes can only reach to IT11 at pose II.

Through the theoretical analysis results, the value of $\sigma \mathrm{AC}_{\mathrm{A} x} / \sigma \mathrm{AD}_{\mathrm{A} x}$ at pose II is larger than that at pose I, which makes the electric cylinder AC producing larger deformation and makes the end-effector producing larger deformation along $x$ direction. The theoretical analysis results are also verified by the experiment results at the two poses. Therefore, the deformation characteristics analysis using DIC is effective to select the proper pose for improving machining accuracy.

According to Equations (3-6), in addition to analysis the deformation influence coefficient, reducing the deformation of the components which has weak stiffness is another way to improve 
the machining accuracy. A comparative experiment is designed that Thomson PC25 series linear electric cylinder is selected to replace the original BXTL150 electric cylinders, as shown in the Figure 7. The equivalent axial stiffness of Thomson electric cylinder is obviously better than that of BXTL150 series electric cylinder. The maximum axial load of Thomson PC25 is $1250 \mathrm{~N}$, the maximum stroke is $600 \mathrm{~mm}$, the maximum speed is $1.33 \mathrm{~m} / \mathrm{s}$, the screw diameter is $10 \mathrm{~mm}$ and the lead is 3mm. Panasonic A6 series low inertia AC servo motor is selected as the power source for the electric cylinder. The prototype for the comparative experiment is shown in Figure 8.

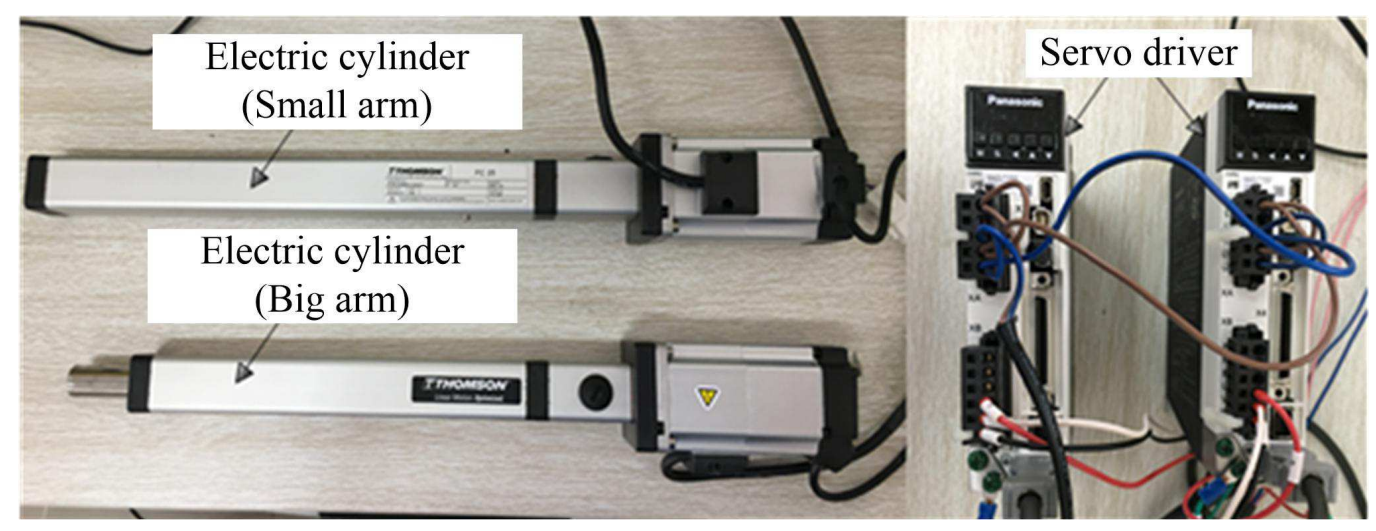

Fig. 7 Thomson series electric cylinders and servo drivers

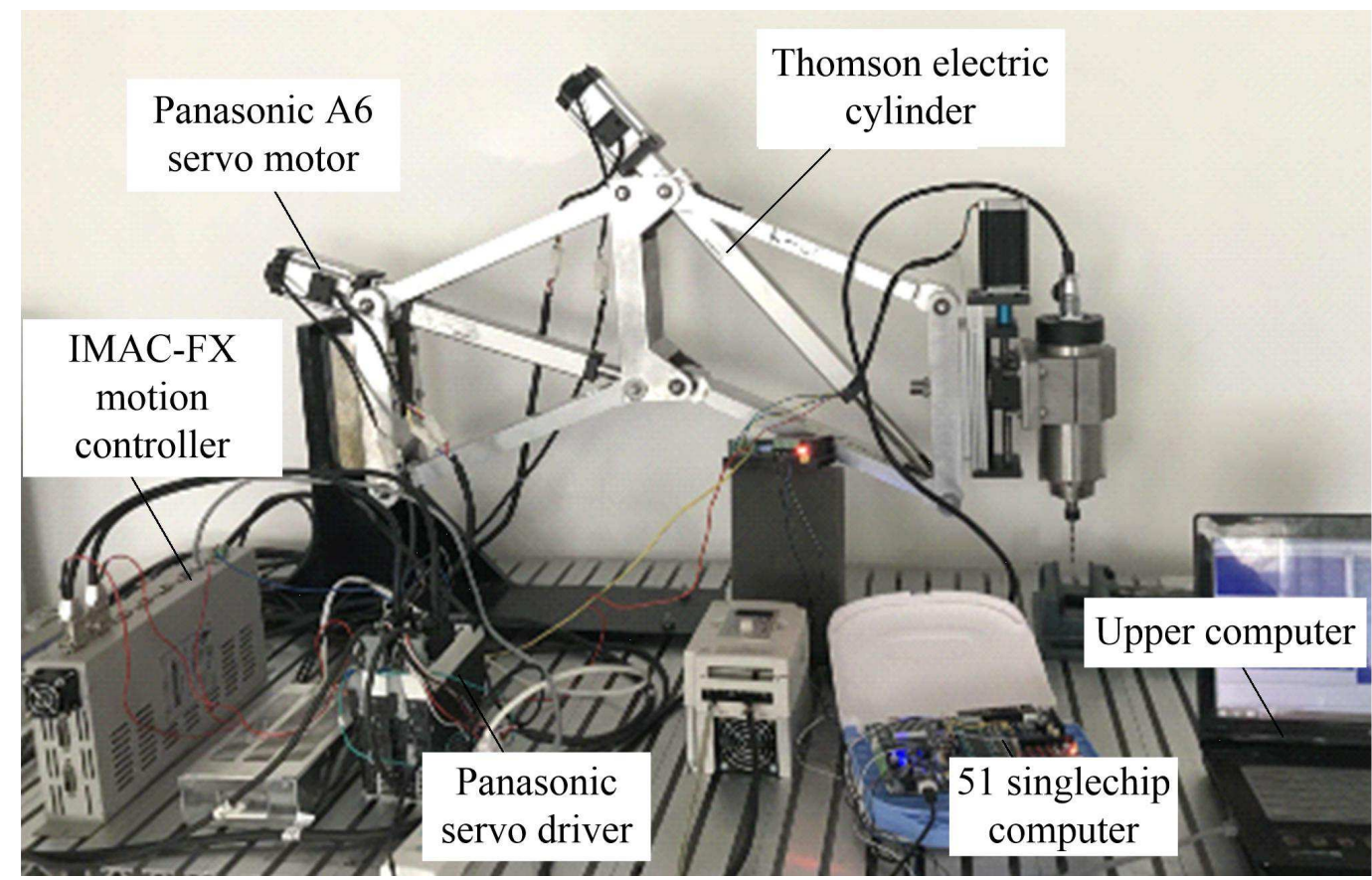

Fig.8 Schematic diagram of the robot prototype (Thomson series electric cylinders)

The drilling experiments are also carried out under the drilling conditions shown in Table 1 . The 
material of the workpiece used for drilling is still 6061 aluminum alloy with thickness of 5mm. The experiment results of angle errors at pose I and pose II are shown in Table 4. According to the experiment results, the average angle error is $0.064^{\circ}$ at pose $\mathrm{I}$, while the average angle error of the holes is $0.072^{\circ}$ at pose II. According to experiment results, the selected Thomson electric cylinders greatly reduce the joint deformation, therefore, the drilling angle error of the prototype is reduced by one order of magnitude compared with the angle error using BXTL150 electric cylinders.

Table 4 Angular errors of drilling holes using the robot prototype (6061 aluminum alloy)

\begin{tabular}{lcc}
\hline No. & Pose I & Pose II \\
\cline { 2 - 3 } H1 & Angle error $\Delta\left(^{\circ}\right)$ & Angle error $\Delta\left(^{\circ}\right)$ \\
\hline H2 & 0.06 & 0.07 \\
H3 & 0.08 & 0.08 \\
H4 & 0.09 & 0.07 \\
H5 & 0.05 & 0.07 \\
H6 & 0.06 & 0.06 \\
H7 & 0.05 & 0.08 \\
H8 & 0.07 & 0.07 \\
H9 & 0.05 & 0.09 \\
H10 & 0.07 & 0.08 \\
H11 & 0.06 & 0.06 \\
H12 & 0.04 & 0.06 \\
H13 & 0.08 & 0.07 \\
H14 & 0.06 & 0.08 \\
\hline
\end{tabular}

The roundness of the drilled holes can be evaluated through four indexes of the maximum aperture, minimum aperture, aperture difference and average aperture of the holes. At the same time, the vertical accuracy of the holes can also be reflected by the roundness errors indirectly. In the experiment, the diameter of the hole drilled with different electric cylinders is measured every $30^{\circ}$ on the circumference of the hole, as shown in Figure 9. 


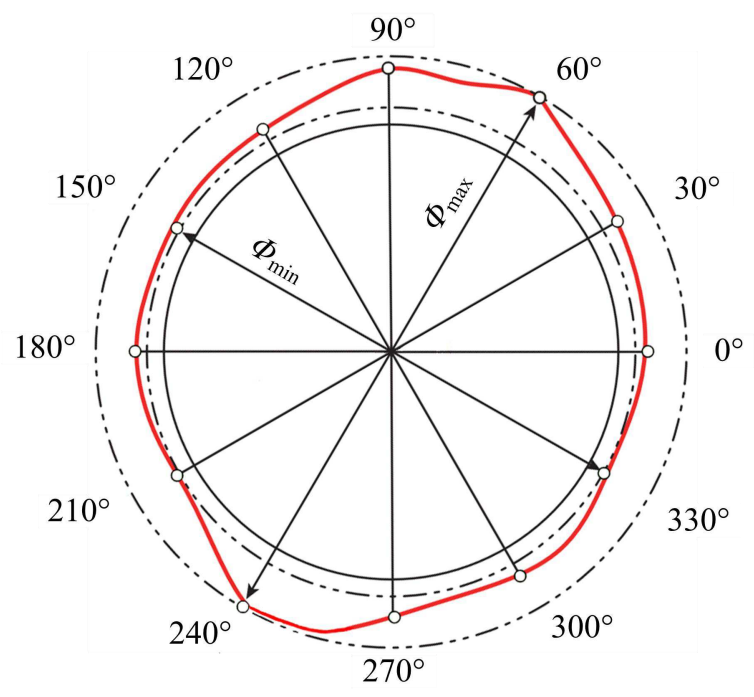

(a) Diameter with BXTL150 electric cylinder

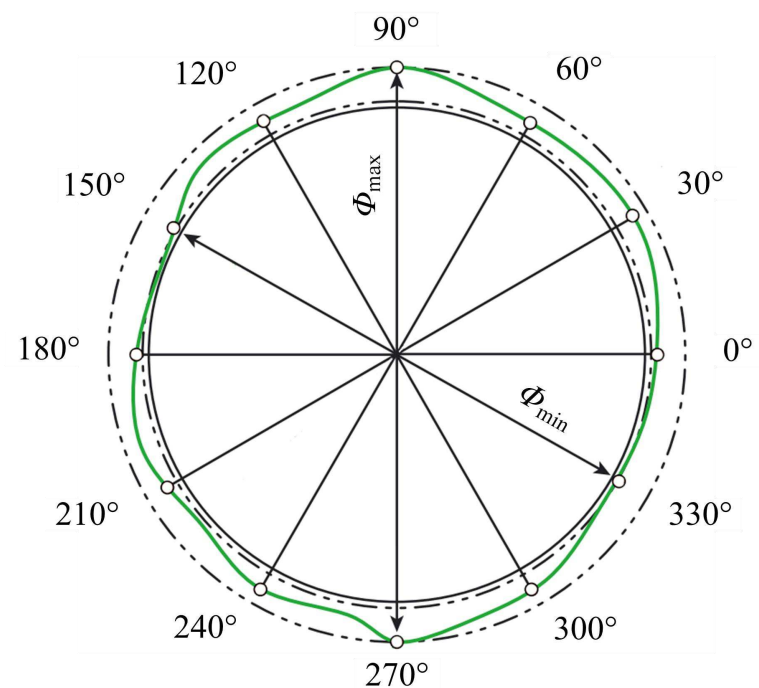

(b) Diameter with Thomson PC25 electric cylinder

Fig. 9 Schematic diagram of diameter distribution for robotic drilling holes

The experimental comparison results of maximum aperture, minimum aperture, aperture difference and average aperture of the drilled holes are shown in Table 5. The maximum tolerance value is $0.006 \mathrm{~mm}$, and the average tolerance value is $0.004 \mathrm{~mm}$ for drilling with Thomson series electric cylinders, while the tolerance value is obviously less than the maximum tolerance value of $0.030 \mathrm{~mm}$ and the average tolerance value of $0.021 \mathrm{~mm}$ for drilling with BXTL150 electric cylinders. The experiment results show that the joint deformation is reduced significantly after replacing the electric cylinders of the robotic arm.

Table 5 Diameter comparison of drilled holes using the robot prototype (6061 aluminum alloy)

\begin{tabular}{ccccccccc}
\hline & & $\mathrm{H} 1$ & $\mathrm{H} 2$ & $\mathrm{H} 3$ & $\mathrm{H} 4$ & $\mathrm{H} 5$ & $\mathrm{H} 6$ & $\mathrm{H} 7$ \\
\hline & $\Phi_{\max }(\mathrm{mm})$ & 5.022 & 5.029 & 5.026 & 5.031 & 5.013 & 5.041 & 5.047 \\
$\begin{array}{c}\text { Electric cylinder } \\
\text { BXTL150 }\end{array}$ & $\Phi_{\min }(\mathrm{mm})$ & 5.005 & 5.009 & 5.009 & 5.007 & 5.001 & 5.011 & 5.020 \\
& $\Delta \Phi(\mathrm{mm})$ & 0.017 & 0.020 & 0.017 & 0.024 & 0.012 & 0.030 & 0.027 \\
& $\Phi_{\text {avg }}(\mathrm{mm})$ & 5.015 & 5.017 & 5.016 & 5.018 & 5.007 & 5.025 & 5.031 \\
\hline $\begin{array}{c}\text { Electric cylinder } \\
\text { Thomson }\end{array}$ & $\Phi_{\max }(\mathrm{mm})$ & 5.004 & 5.006 & 5.009 & 5.005 & 5.006 & 5.007 & 5.006 \\
PC25 & $\Phi_{\min }(\mathrm{mm})$ & 5.002 & 5.002 & 5.003 & 5.001 & 5.004 & 5.001 & 5.002 \\
& $\Delta \Phi(\mathrm{mm})$ & 0.002 & 0.004 & 0.006 & 0.004 & 0.002 & 0.006 & 0.004 \\
\hline
\end{tabular}


In the further experiments, 7075 aluminum alloy workpieces with higher strength are selected, and the thickness of the workpiece increases to $8 \mathrm{~mm}$. The drilling parameters are still selected as shown in Table 1. Under this condition, the axial drilling force for drilling $5 \mathrm{~mm}$ hole increases to about $102.3 \mathrm{~N}$, and the experimental effect of the robotic arm prototype drilling on 7075 aluminum alloy workpiece is shown in Figure 10. The angle error results of the robot prototype for drilling $5 \mathrm{~mm}$ holes on 7075 aluminum alloy workpieces are shown in Table 6. As shown in Table 6, the average angle errors of the robot prototype drilling along the $x$ direction, $y$ direction and $z$ direction are $0.104^{\circ}, 0.281^{\circ}$ and $0.110^{\circ}$, respectively.

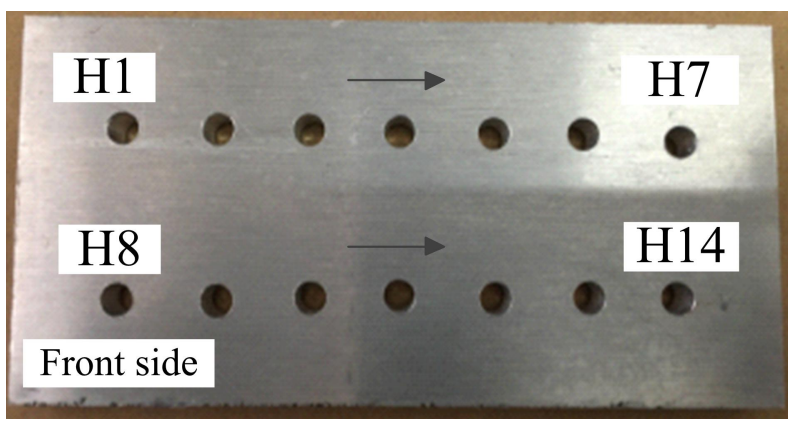

(a) $x$ direction (Front side)

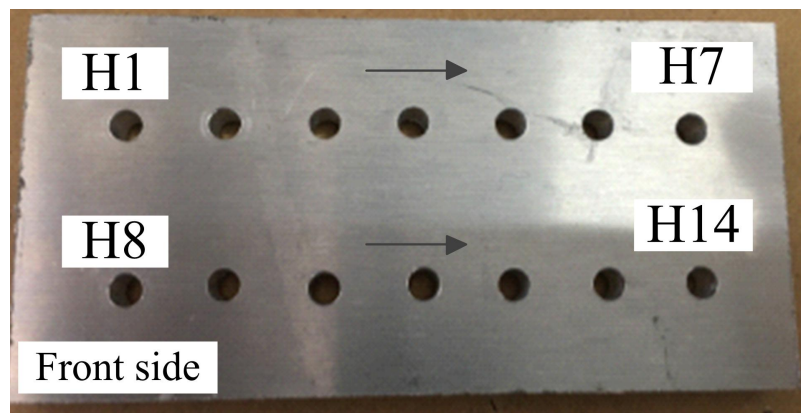

(c) $y$ direction (Front side)

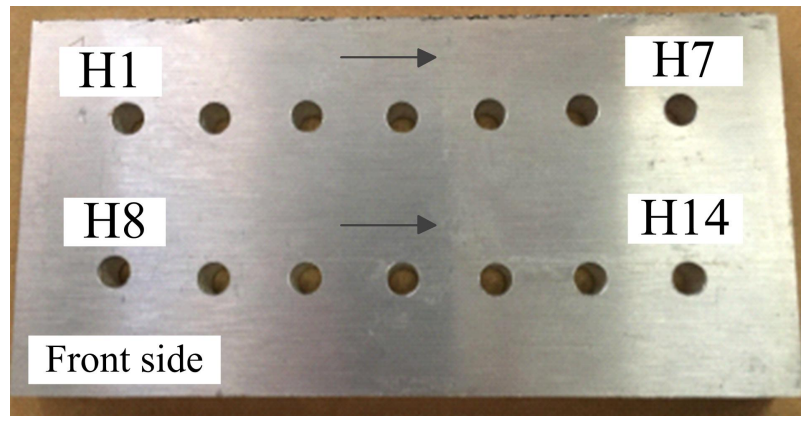

(e) $z$ direction (Front side)

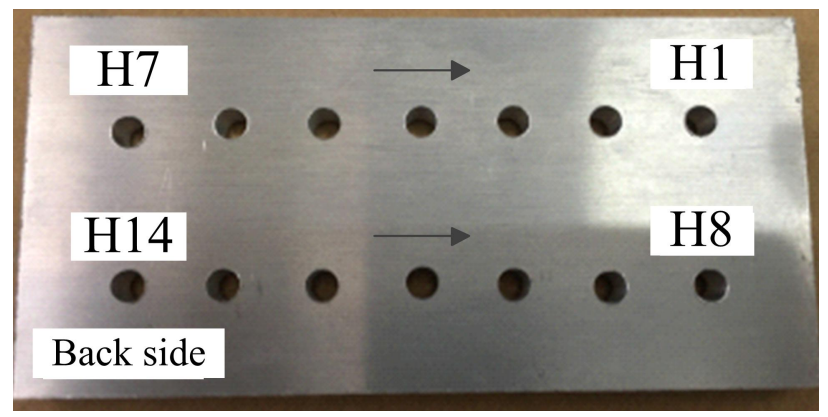

(b) $x$ direction (Back side)

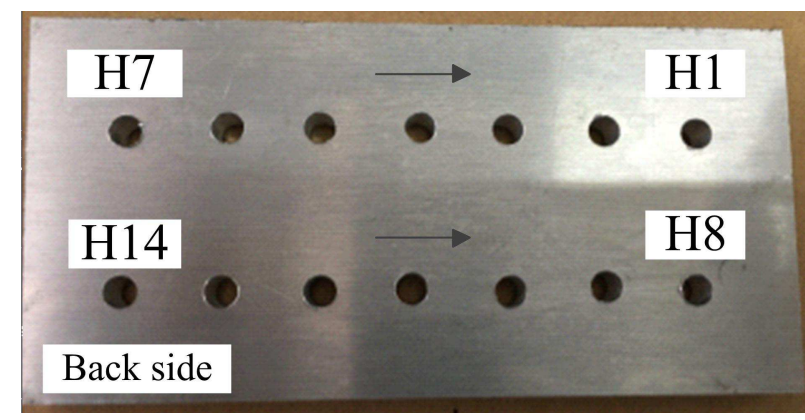

(d) $y$ direction (Back side)

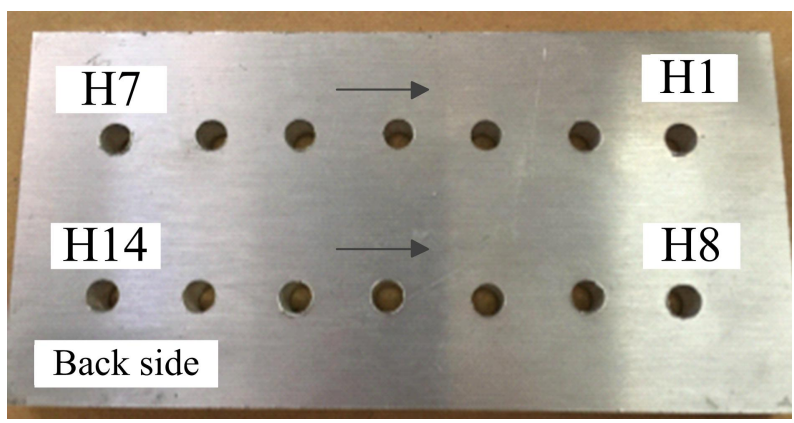

(f) $z$ direction (Back side)

Fig. 10 Drilling experiment effect using the robot prototype (7075 aluminum alloy) 
Table 6 Angular errors of drilled holes using the robot prototype (7075 aluminum alloy)

\begin{tabular}{|c|c|c|c|c|c|c|c|}
\hline \multirow[b]{2}{*}{ No. } & \multicolumn{3}{|c|}{ Angle error $\Delta\left(^{\circ}\right)$} & \multirow[b]{2}{*}{ No. } & \multicolumn{3}{|c|}{ Angle error $\Delta\left(^{\circ}\right)$} \\
\hline & $\begin{array}{c}x \\
\text { direction }\end{array}$ & $\begin{array}{c}y \\
\text { direction }\end{array}$ & $\begin{array}{c}z \\
\text { direction }\end{array}$ & & $\stackrel{x}{\text { direction }}$ & $\begin{array}{c}y \\
\text { direction }\end{array}$ & $\begin{array}{c}z \\
\text { direction }\end{array}$ \\
\hline H1 & 0.10 & 0.28 & 0.13 & $\mathrm{H} 8$ & 0.11 & 0.30 & 0.14 \\
\hline $\mathrm{H} 2$ & 0.14 & 0.31 & 0.11 & H9 & 0.10 & 0.29 & 0.12 \\
\hline $\mathrm{H} 3$ & 0.09 & 0.25 & 0.09 & $\mathrm{H} 10$ & 0.08 & 0.27 & 0.08 \\
\hline $\mathrm{H} 4$ & 0.12 & 0.30 & 0.10 & H11 & 0.13 & 0.24 & 0.09 \\
\hline H5 & 0.09 & 0.29 & 0.09 & H12 & 0.12 & 0.29 & 0.11 \\
\hline H6 & 0.11 & 0.33 & 0.13 & H13 & 0.10 & 0.26 & 0.10 \\
\hline $\mathrm{H} 7$ & 0.08 & 0.26 & 0.12 & H14 & 0.09 & 0.27 & 0.13 \\
\hline
\end{tabular}

Table 7 shows the aperture distribution results of the robot prototype for drilling $5 \mathrm{~mm}$ holes on 7075 aluminum alloy workpieces along $z$ direction, and the tolerance level of the drilled holes can be reached to IT6. Because of the high vertical accuracy of drilling, the burr of the holes is also significantly reduced, even if the feed force increases, awesome accuracy of drilling can be ensured.

Table 7 Diameters of drilling holes in $z$ direction using the robot prototype (7075 aluminum alloy)

\begin{tabular}{cccccccc}
\hline & $\mathrm{H} 1$ & $\mathrm{H} 2$ & $\mathrm{H} 3$ & $\mathrm{H} 4$ & $\mathrm{H} 5$ & $\mathrm{H} 6$ & $\mathrm{H} 7$ \\
\hline$\Phi_{\max }(\mathrm{mm})$ & 5.011 & 5.012 & 5.011 & 5.010 & 5.011 & 5.010 & 5.009 \\
$\Phi_{\min }(\mathrm{mm})$ & 5.006 & 5.008 & 5.005 & 5.003 & 5.007 & 5.005 & 5.003 \\
$\Delta \Phi(\mathrm{mm})$ & 0.005 & 0.004 & 0.006 & 0.007 & 0.004 & 0.005 & 0.006 \\
$\Phi_{\text {avg }}(\mathrm{mm})$ & 5.009 & 5.010 & 5.008 & 5.007 & 5.009 & 5.008 & 5.006 \\
\hline \hline & $\mathrm{H} 8$ & $\mathrm{H} 9$ & $\mathrm{H} 10$ & $\mathrm{H} 11$ & $\mathrm{H} 12$ & $\mathrm{H} 13$ & $\mathrm{H} 14$ \\
\hline$\Phi_{\max }(\mathrm{mm})$ & 5.009 & 5.011 & 5.010 & 5.011 & 5.012 & 5.009 & 5.013 \\
$\Phi_{\min }(\mathrm{mm})$ & 5.003 & 5.006 & 5.002 & 5.005 & 5.005 & 5.004 & 5.006 \\
$\Delta \Phi(\mathrm{mm})$ & 0.006 & 0.005 & 0.008 & 0.006 & 0.007 & 0.005 & 0.007 \\
$\Phi_{\text {avg }}(\mathrm{mm})$ & 5.008 & 5.009 & 5.006 & 5.008 & 5.009 & 5.007 & 5.010 \\
\hline
\end{tabular}




\section{Conclusions}

In this paper, the deformation influence coefficient (DIC) is proposed based on the Strain energy method and Castigliano theorem to evaluate the deformation characteristics of the robotic arm with hybrid open- and closed-loop kinematic chains. By defining the deformation influence coefficient, the deformation influence of internal components in the workspace can be analyzed. According to the DIC and the component stiffness, the machining mode of the robotic arm can be reasonably planned to reduce the deformation in the machining process. In order to verify the influence of DIC on the machining accuracy, the comparative robotic drilling experiments are carried out. The theoretical and experiment results show that the pose can be selected according to the DIC which is beneficial to improve machining accuracy, as well as improve the equivalent stiffness of the key component. In addition, compared with the serial industrial robot, the advantage of the robotic arm with hybrid kinematic chains is that the electric cylinders, links and other components can be selected according to the machining accuracy requirements. This feature makes the robotic arm more flexible to suit for different tasks.

Funding This work was supported by the Liaoning Doctor Scientific Research Initial Fund (No.2021-BS-160), and the Research Support Fund for Introducing High-Level Talents to Shenyang Ligong University (No. 1010147000821).

Data availability Not applicable

Code availability Not applicable

\section{Declarations}

Ethics approval The work was an original research that has not been published previously and not under consideration for publication elsewhere, in whole or in part.

Consent to participate The authors all approved to participate.

Consent to publication It is approved by all authors for publication.

Conflict of interest The authors declare no competing interests. 


\section{References}

[1] Bu Y, Liao WH, Tian W, Zhang J, Zhang L. Stiffness analysis and optimization in robotic drilling application[J]. Precision Engineering, 2017, 53(49): 388-400.

[2] Slavkovic NR, Milutinovic DS, Glavonjic MM. A method for off-line compensation of cutting force-induced errors in robotic machining by tool path modification[J]. International Journal of Advanced Manufacturing Technology, 2014, 70(9-12): 2083-2096.

[3] Luo HT, Zhao FQ, Guo SW, Yu CS, Liu GM, Wu TK. Mechanical performance research of friction stir welding robot for aerospace applications[J]. International Journal of Advanced Robotic System, 2021, 18(1): 1-11.

[4] Xu P, Cheung CF, Li B, Wang CJ, Zhao CY. Design, dynamic analysis, and experimental evaluation of a hybrid parallel-serial polishing machine with decoupled motions[J]. Journal of Mechanisms and Robotics-Transactions of the ASME, 2021, 13(6): 1008-1-13.

[5] Janez G, Timi K, Karl G, Miran B. Accuracy improvement of robotic machining based on robot's structural properties[J]. International Journal of Advanced Manufacturing Technology, 2020, 108(5-6): 1309-1329.

[6] Xie H, Li WL, Zhu DH, Yin ZP, Ding H. A Systematic Model of Machining Error Reduction in Robotic Grinding[J]. IEEE/ASME Transactions on Mechatronics, 2020, 25(6): 2961-2972.

[7] Wei W, Cai GW, Gong JJ, Peng SX. Modeling and Analysis of the Stiffness Distribution of Host-Parasite Robots[J]. IEEE Access, 2021, 9: 86300-86320.

[8] Zhao J, Duan YX, Xie BY, Zhang ZQ. FSW robot system dimensional optimization and trajectory planning based on soft stiffness indices[J]. Journal of Manufacturing Process, 2021, 63: 88-97.

[9] Li YJ, Gao GB, Liu F. Positioning Error Compensation for Industrial Robots Based on Stiffness Modelling[J]. Complexity, 2020: 1-13.

[10] Zhang JL, Liao WH, Bu Y, Tian W, Hu JS. Stiffness properties analysis and enhancement in robotic drilling application[J]. International Journal of Advanced Manufacturing Technology, 2020, 106(11-12): 5539-5558.

[11] Bu Y, Liao WH, Tian W, Zhang L, Li DW. Modeling and experimental investigation of Cartesian compliance characterization for drilling $\operatorname{robot}[\mathrm{J}]$. International Journal of Advanced Manufacturing Technology, 2017, 91(9-12): 3253-3264.

[12] Lin JZ, Ye CC, Yang JX, Zhao H, Ding H, Luo M. Contour error-based optimization of the 
end-effector pose of a 6 degree-of-freedom serial robot in milling operation[J]. Robotics and Computer-Integrated Manufacturing, 2022, 73:1-11.

[13] Zhu WD, Li GH, Dong HY, Ke YL. Positioning error compensation on two-dimensional manifold for robotic machining[J]. Robotics and Computer-Integrated Manufacturing, 2019, 59: 394-405.

[14] Yin FC, Ji QZ, Wang CZ. Research on machining error prediction and compensation technology for a stone-carving robotic manipulator[J]. International Journal of Advanced Manufacturing Technology, 2021, 115(5-6): 1683-1700.

[15] Ye CC, Yang JX, Zhao H, Ding H. Task-dependent workpiece placement optimization for minimizing contour errors induced by the low posture-dependent stiffness of robotic milling[J]. International Journal of Mechanical Sciences, 2021, 205(106601): 1-16.

[16] Li GZ, Zhang FH, Fu YL, Wang SG. Joint Stiffness Identification and Deformation Compensation of Serial Robots Based on Dual Quaternion Algebra[J]. Applied Sciences, 2019, 9(1): $1-18$.

[17] Frommknecht A, Kuehnle J, Effenberger I, Pidan S. Multi-sensor measurement system for robotic drilling[J]. Robotics and Computer-Integrated Manufacturing, 2017, 47: 4-10.

[18] Luo Z, Zhao XY, Liang L, Wang F. Structure Optimization of Slender Robot Arm Based on Sensitivity Analysis[J]. Mathematical Problems in Engineering, 2012: 1-17.

[19] Li J, Xie FG, Liu XJ, Mei B, Li HJ. A spatial vector projection based error sensitivity analysis method for industrial robots[J]. Journal of Mechanical Science and Technology, 2018, 32(6): 2839-2850.

[20] Wang YH, Tang XQ, Xiang CY, Hou SH. Force sensitivity analysis and scale design of Stewart parallel manipulator[J]. Advances in Mechanical Engineering, 2021, 13(7):1-17.

[21] Liang J. A research on the mounted configuration of end-effector for robotic drilling[J]. Robotica, 2015, 33(10): 2156-2165.

[22] Luo HT, Fu J, Wang P, Liu JG, Zhou WJ. Design optimization of the ram structure of friction stir welding robot[J]. Mechanics of Advanced Materials and Structures, 2020, 27(2): 108-118. 